\title{
Parental Involvement in Child's Development: Father vs. Mother
}

\author{
Yeoh Si Han, Woo Pei Jun \\ Department of Psychology, Sunway University, Petaling Jaya, Malaysia \\ Email: pjwoo@sunway.edu.my
}

Received May, 2013

\begin{abstract}
This study aims to investigate on Malaysian young adults' perceived father and mother involvement. A questionnaire survey with Father Involvement Scale, and Mother Involvement Scale was carried out on 100 male and 100 female local university and college student aged 18 and 25 years old. The findings show that mothers engaged more in expressive and mentoring/advising involvement as compared to fathers. However, there is no difference between fathers and mothers in instrumental involvement. This study gives us a better understanding on the pattern of parental involvement in Malaysia and hence helps to promote better parent-child relationship.
\end{abstract}

Keywords: Parental Involvement; Father; Mother

\section{Introduction}

For years, theorists and scholars have been acknowledged that fathers and mothers play a different role in family systems (see [1]). Fathers assume the role of breadwinner, working outside and earning a living for the family while mothers are usually the primary caregivers, taking care and fulfilling the needs of the children. Half a decade ago, Parsons and Bales' [2] suggested that fathers were more engaged in instrumental functions, such as disciplining children and providing income whereas mothers were expected to be involved in expressive functions such as care giving, sharing activities and companionship. Today, women are getting more involved in the workforce as compared to a few decades before. Hence, will this structural distribution of parental involvement be remained? This study aims to investigate whether fathers and mothers involve differently in their children's development in terms of the three dimensions of involvement (i.e., expressive involvement [EI], instrumental involvement [II], and mentoring/advising involvement [MAI]).

\section{Parental Involvement}

\subsection{Definitions and Theories}

Many researchers have defined parental involvement differently based on their purposes of studies [3-5]. Singh et al. [3] noted that parental involvement has been considered a multidimensional construct with multiple domains. A widely used model by Lamb and colleagues [4] conceptualised three typologies of involvement: (1) Interaction - one to one interaction with the child including feeding, playing and reading; (2) Accessibility - availability to the child, even if not directly involving; And (3) responsibility - assuming responsibility for child care and welfare.

On the other hand, Mo and Singh [5] described parental involvement as "initiated by the parents as part of their responsibility for children's psychosocial and educational development” (p.1). According to Mo and Singh [5], parental involvement consisted of three components: parent-child relationship, parental involvement in school, and parents' educational aspirations for their children. These involvements have found to be predictive to students' educational engagement and performance.

Theory of structure-functionalism [6] suggested that individuals in society have separate and distinct roles; the responsibility to complete these roles is necessary for survival. Hence, when this concept is applied in family, fathers and mothers are expected to function differently in order to maintain the harmony in the family system. Finley and Schwartz [7] found a similar differentiation of parental involvement and have further expanded the two components (i.e., EI and II) into three -EI, II and MAI. These distinctions were found to be applied well to young adults' perceptions of parental involvement [8].

Drawing on previous works on parental involvement $[2,7,8]$, this study defines parental involvement as parents' interaction and engagement in a child's life, which promote some aspects of development. This involvement encompasses three dimensions: (1) EI - leisure, fun, and 
play, companionship, sharing activities/interests, caregiving, and promoting emotional, social, physical, and spiritual development; (2) II - developing responsibility and independence, encouraging ethical/moral and career development, providing income, discipline, being protective, and concern about school or homework; (3) MAI developing competence, mentoring/teaching, advising, and intellectual development.

\subsection{Research Evidences on Parental Involvement: Father vs. Mother}

Thompson and Walker [9] noted that once women and men become parents, they tend to relate to their children differently and do different things with and for their children. This insight suggests the complication that lies beneath the experience of parenthood and the importance of revealing the unique and similar aspects of the parental experience for men and women.

$E I$. Research has shown that in families, women often take primary responsibility for emotional support, nurturing, establishing routines, setting rules and organising their children, especially when the children are young [10]. Besides, another study that researched on parental involvement of Malay and Chinese families from peninsular Malaysia found that mothers generally spent more time than fathers in childcare task [11].

Furthermore, Yeung and colleagues' [12] study which examined on 1761 children aged 0 to12 years old revealed that as compared to fathers, mothers generally engaged more in personal care activities, play and companionship activities, achievement-related activities, household activities, and social activities. Additionally, research findings on 1714 young adult university students $(M$ age $=19.9$ years $)$ showed that mothers were perceived to be significantly more involved in the domains of expressive dimensions, especially in the area of emotional development, caregiving, spiritual development, companionship and social development [8].

Nonetheless, there were also researchers and scholars who proposed that fathers are getting more involved in expressive functions [13-15]. Giele and Holst [13] found that there were changes in gender roles as a result of social revolution during the 1960s and 1970s. Therefore, they presumed that fathers are now become more involved in child rearing and activities at home (e.g., caregiving). Besides, reviews by scholars also suggested that fathers are getting more engaged in expressing areas such as companionship and care giving (e.g., [15]). Guided by the theory of structure-functionalism and findings from the majority studies, it is predicted that mothers as compared to fathers enrol more in expressive functions.

II. Traditional aspects of II are often characterised by fathering roles - providing income, discipline, protecting, moral guide, and encouraging responsibility. A state- wide, random household telephone survey of 1010 adults on the social norms about expectations of fathers revealed that a majority of participants agreed that most fathers engaged in the areas of financial support, protection, and moral or faith-based guidance [16]. Another study [17] researched on 1492 young adult university students from intact families also found that fathers were significantly more involved in instrumental functions as compared to expressive functions. The findings also showed that seven out of the eight most heavily endorsed fathering functions were from the instrumental dimension (i.e., providing income, being protective, discipline, responsibility, moral/ethical, independence, and career). Additionally, to examine the moderating effect of ethnicity in fathering functions, the study also revealed that Asian fathers were significantly more involved in the instrumental dimensions as compared to the expressive dimension of involvement [17].

Furthermore, studies on specific ethnic groups also found similar findings (e.g., [18-20]). One of these studies illustrated that African American fathers were characterised as more involved in instrumental functions such as monitoring but as relatively unaffectionate [18]. Besides, Asian fathering role has also appeared to lend itself more to instrumental rather than expressive functions [19]. Lastly, a study using national-level data to examine American fathers' involvement in child rearing for children aged 5 to 18 years revealed that Hispanic fathers participated more in cognitive domains, such as reinforcing family rules and monitoring homework [20].

On the contrary, study by Finley et al. [8] showed that other than proving incomes, fathers were significantly less involved in all domains of parental involvement (i.e., EI, II, and MAI). However, there was a trend showing that fathers were more involved in instrumental function as compared to expressive functions [8].

Although fewer studies have been researched on fathers' II in comparative to that of mothers, drawing on most of the supporting findings that fathers engaged more in II [16-20], this study predicts that fathers would participate more in this dimension of involvement as compared to mothers.

MAI. This dimension of involvement is indeed conceptually overlapping between expressive and instrumental parenting, thus limited studies are done particularly on this dimension of involvement. Among these limited studies, Finley et al. [8] found that mothers as compared to fathers were more engaged in MAI. Specifically, the findings indicated that mothers were significantly more involved in the domains of advising, intellectual development, mentoring, and developing competence. Additionally, Yeung and colleagues' study also revealed that mothers relatively spent more time with their children as compared to fathers in teaching related 
activities, such as studying, doing homework, reading, and in educational lessons [12].

Based on the promising findings from the previous studies [8, 12], it is of interest to explore whether parents in Malaysia follow this pattern of involvement. Therefore, this study expects to see that mothers show higher level of involvement in this mentoring/advising dimension as compared to fathers.

\section{Hypotheses}

Specifically, this study tested three hypotheses: (1) Mothers as compared to fathers involve more in EI; (2) Fathers as compared to mothers involve more in II; And (3) mothers as compared to fathers involve more in MAI.

\section{Methodology}

\subsection{Participants}

A single survey was conducted to 100 male and 100 female students (aged 18 and 25 years old, $\mathrm{M}=21.07$, SD $=1.75$ ) from three public universities and one private university in Malaysia. Among the participants, there were 22 Malays (11.0\%), 162 Chinese (81.0\%), and 16 Indians (8.0\%). In terms of religion, there were 22 Muslims (11.0\%), 33 Christians (16.5\%), 120 Buddhists (60.0\%), 11 Hindus (5.5\%) and 14 participants (7.0\%) who had other religions. All participants in this study were single and from intact families. Regarding the parents' working status, 174 (87.0\%) participants' fathers were reported as working, 3 (1.5\%) of the participants' fathers were not working, and 23 (11.5\%) of their fathers have retired. For mothers' working status, participants reported that $89(44.5 \%)$ of their mothers were still working, 101 (50.5\%) participants' mothers were not working, and $10(5.0 \%)$ of their mothers have retired.

\subsection{Procedures}

A brief explanation of the study was given to the participants and written consents were obtained. Participants were given approximately 15 minutes to complete the questionnaires. Participants were also allowed to withdraw from this study at any point of time without prejudice.

\subsection{Measurement}

Reported father and mother involvement. Young adults' reports of father and mother involvement were measured using the Father Involvement Scale (Finley \& Schwartz, 2004) and Mother Involvement Scale (Finley et al., 2008). These two scales consisted of similar content except for the terms "father" and "mother" are stated accordingly. The scales consisted of 20 domains of parenting and can be categorised into three subscales: (1) EI - caregiving, companionship, sharing activities, emotional development, social development, spiritual development, physical development, and leisure, play and fun; (2) II discipline, being protective, providing income, school/ homework, ethical/moral development, developing responsibility, career development, and developing independence; and (3) MAI - intellectual development, developing competence, mentoring/teaching, and giving advice.

The response rating for reported involvement is a linear response rating, which ranges from 1 (never involved) to 5 (always involved). Higher score indicates higher level of involvement. No items are reversed scores. Total scores for reported involvement can be created by summing the respective domain ratings. Possible scores for these totals range from 20 to 100 . Subscale scores can be generated by summing the domain scores of particular subscale and dividing the number of items.

These scales had excellent internal consistencies (Finley et al., 2008). For the reported father involvement, Cronbach's alpha coefficients were .91 for EI, .90 for II, and 0.88 for MAI (Finley et al., 2008). For the reported mother involvement, Cronbach's alpha coefficients were .86 for EI, .80 for II, .82 for MAI (Finley et al., 2008).

\section{Results}

A paired sample $t$ test was conducted to examine the differences of fathers and mothers in the three dimensions of involvement in a child's development. For EI, the result reveals that there is a significant difference between father EI $(M=3.03, S D=0.67)$ and mother EI $(M=3.58$, $S D=0.72), t(199)=-10.04, p<.01$. This result indicates that mothers were perceived to be more involved in EI as compared to father.

For II, the result shows that there is no significant difference between father II and mother II, $t(199)=-1.12, p$ $>.05$.

For MAI, the result reveals that there is a significant difference between father MAI $(M=3.37, S D=.83)$ and mother MAI $(M=3.63, S D=.81), t(199)=-4.16 p$ $<.01)$. This result indicates that mothers were perceived to be more involved in MAI as compared to fathers.

To further analyse the differences between fathers and mothers in the involvement domains, another paired sample $t$ test was conducted. The results show that there is a significant difference between fathers and mothers in all the eight domains of EI - emotional development (fathers' $M=2.86, S D=0.97$ vs. mothers' $M=3.67, S D=$ 1.02), $t(199)=-9.38, p<.01$; social development (fathers' $M=3.06, S D=1.04$ vs. mothers' $M=3.56, S D=$ 1.06), $t(199)=-5.23, p<.01$; spiritual development (fathers' $M=3.08, S D=1.18$ vs. mothers' $M=3.55, S D=$ 1.09), $t$ (199) $=-4.73, p<.01$; physical development (fa- 
thers' $M=2.82, S D=1.01$ vs. mothers' $M=3.26, S D=$ 1.13), $t$ (199) $=-4.46, p<.01$; leisure, fun, and play (fathers' $M=2.99, S D=1.11$ vs. mothers' $M=3.25, S D=$ 1.09), $t(199)=-2.73, p<.01$; sharing activities or interest (fathers' $M=2.83, S D=1.00$ vs. mothers' $M=3.32$, $S D=1.03, t(199)=-5.63, p<.01$; caregiving(fathers' $M$ $=3.61, S D=1.04$ vs. mothers' $M=4.28, S D=.84), t$ (199) $=-8.42, p<.01$; and companionship (fathers' $M=$ 3.01, $S D=1.03$ vs. mothers' $M=3.75, S D=1.03$ ), $t$ (199) $=-8.72, p<.01$ (see Table 1). These results indicate that mothers as compared to fathers were significantly more involved in all the eight domains in EI.

For II, the results show that there is a significant difference between fathers and mothers in two domains providing income (fathers' $M=3.98, S D=1.11$ vs. mothers' $M=3.39, S D=1.20), t(199)=5.49, p<.01$, and school/homework (fathers' $M=2.43, S D=1.15$ vs. mothers' $M=3.01, S D=1.27), t(199)=-6.27, p<.01$ (see Table 2). These results indicate that fathers were more involved in providing income as compared to mothers. In contrast, mothers as compared to fathers were more engaged in their children's schoolwork. No significant difference was found between fathers and mothers in other domains - ethical/moral development, career development, developing responsibility, developing independence, being protective, and discipline.

In terms of MAI, the results show that there is a significant difference between fathers and mothers in three out of the four domains - intellectual development (fathers' $M=3.47, S D=1.02$ vs. mothers' $M=3.67, S D=$ 1.01), $t(199)=-2.34, p<.05$, mentoring/teaching (fathers' $M=3.04, S D=1.17$ vs. mothers' $M=3.54, S D=$ 1.10), $\quad t(199)=-5.39, p<.01$, and advising (fathers' $M$ $=3.73, S D=1.03$ vs. mothers' $M=3.92, S D=.98), t$ $(199)=-2.25, p<.05$ (see Table 1). No significant difference was found between fathers and mothers in the developing competence domain. Hence, the results indicate that mothers as compared to fathers engaged more in the domains of intellectual development, mentoring or teaching, and advising.

\section{Discussions}

This study was designed to examine the differential involvement of fathers and mothers in child's development. The results support the first hypothesis and shows that mothers were significantly more involved in expressive functions than fathers. This finding reinforces Parsons and Bales' [12] structural distribution of parental involvement, and is in accordance to previous findings which supported mothers' greater involvement in caregiving, companionship, emotional development and other expressive tasks as compared to fathers[8,11,12].

For II, the results do not support the second hypothesis and show that there is no significant difference between fathers and mothers in terms of their instrumental involvement. Neither this finding supports Parsons and Bales' [12] structural distribution of parental roles where fathers are expected to assume the instrumental functions more than mothers nor Finley and colleagues' [8] opposing findings that mothers as compared to fathers significantly more engaged in II.

However, when each instrumental domain is taken into consideration, fathers were reported as often involved in providing income and were significantly more involved than mothers. Similar findings have shown fathers remained to be the financial support for the household and contributed a higher proportion of household income to the families [12, 16]. Moreover, this finding is not unexpected given that the number of fathers in this study who were reported as working doubled the number of those of mothers. Based on these findings, a possible explanation for the non-significant result between fathers and mothers in the instrumental dimension could be that fathers' greater involvement in providing income might compromise the time spending with their children in developing responsibility or independence, disciplining, or dealing with school and homework. Fathers' earning and work

Table 1. Mean score of reported involvement by parent and domain.

\begin{tabular}{|c|c|c|c|}
\hline \multirow{2}{*}{ Variable } & \multicolumn{2}{|c|}{ Mean Score } & \multirow{2}{*}{$t(199)$} \\
\hline & Father & Mother & \\
\hline \multicolumn{4}{|l|}{ EI } \\
\hline Emotional development & 2.86 & 3.67 & $-9.38 * *$ \\
\hline Social development & 3.06 & 3.56 & $-5.23 * *$ \\
\hline Spiritual development & 3.08 & 3.55 & $-4.73 * *$ \\
\hline Physical development & 2.82 & 3.26 & $-4.46^{* *}$ \\
\hline Leisure, fun, play & 2.99 & 3.25 & $-2.73 * *$ \\
\hline Sharing activities/interest & 2.83 & 3.32 & $-5.63 * *$ \\
\hline Caregiving & 3.61 & 4.28 & $-8.42^{* *}$ \\
\hline Companionship & 3.01 & 3.75 & $-8.72 * *$ \\
\hline \multicolumn{4}{|l|}{ II } \\
\hline Moral development & 3.67 & 3.81 & -1.66 \\
\hline Career development & 3.39 & 3.44 & -.57 \\
\hline Developing responsibility & 3.70 & 3.82 & -1.37 \\
\hline Developing independence & 3.63 & 3.66 & -.34 \\
\hline Providing income & 3.98 & 3.39 & $5.49^{* *}$ \\
\hline Being protective & 3.87 & 3.90 & -.45 \\
\hline Discipline & 3.66 & 3.78 & -1.46 \\
\hline School/homework & 2.43 & 3.01 & $-6.27 * *$ \\
\hline \multicolumn{4}{|l|}{$M A I$} \\
\hline Intellectual development & 3.47 & 3.67 & $-2.34^{*}$ \\
\hline Developing competence & 3.26 & 3.42 & -1.86 \\
\hline Mentoring/teaching & 3.04 & 3.54 & $-5.39 * *$ \\
\hline Advising & 3.73 & 3.92 & $-2.25^{*}$ \\
\hline
\end{tabular}

${ }^{*} p<.05 .{ }^{* *} p<.01$. 
hours were found to be significantly and negatively affecting their level of involvement with children [21], especially during weekdays [12].

On the other hand, mothers were reported to be significantly more involved than fathers in school or homework domain. This outcome is congruent with Hossain and Anziano's [21] finding that mothers as compared to fathers were more involved in academic work such as homework, buying school supplies, school contacting and tutor arrangement. For other instrumental domains, the involvement of fathers did not differ from those of mothers. Both parents were generally rated as often involved in ethical or moral development, developing responsibility, developing independence, being protective, and in disciplining; whereas for career development domain, both parents were rated as sometimes involved.

Despite the non significant results for II, there was a trend showed that fathers generally more involved in instrumental dimension as compared to mentoring/advising and expressive dimensions. The mean score of father II indicated that fathers were generally rated as often involved as compared to EI and MAI which were rated as sometimes involved. This trend appears to support the previous ethnicity studies which revealed that fathers tend to be more involved in instrumental functions rather than expressive functions [19-21].

In terms of MAI, the result supports the third hypothesis and is in congruence with previous findings [8, 12]. The finding shows that mothers were significantly more involved than fathers in the MAI. Specifically, mothers were more involved than fathers in the areas of intellectual development, mentoring/teaching and advising. In deference to Parsons and Bales, if the most highly endorsed parental involvement for fathers (providing income) and for mothers (caregiving) are considered, the findings are indeed fully supportive of Parsons and Bales' [2] theoretical formulation.

This study has several strengths. Firstly, the scales that are used in this study have high reliability and validity. Secondly, questionnaire survey with closed-ended questions not only facilitates the process of scoring but also result interpretation. In addition, this study is also one of the few studies that look into the differential functions of fathers and mothers in the three dimensions of involvement. Therefore, this study provides some base level data for Malaysia parenting research and for future comparison. In particular, the use of retrospective report in this study provides uniquely valuable information regarding the young adults' long term perception of parental involvement in their lives instead of parents' report on the level of involvement.

Nevertheless, the findings of the present study should also be considered in light of several limitations. Firstly, the sample in this study is not representative of the current Malaysian population due to the overrepresentation of Chinese ethnicity. Secondly, the use of university samples raises genera liability issues and may have screened out young adults from lower educational background or those with intellectual, social, or emotional challenges. Thirdly, although the use of retrospective reports allows young adults to reflect back on their parental involvement from a more "mature" perspective, this method is also vulnerable to recall biases [22]. Lastly, there may be possibility that young adults' reports of their parents' past involvement are affected by their current relationship with their parents. Therefore, these limitations should be kept in mind when interpreting the results.

Several suggestions for future research follow from the present findings and limitations can be made. Firstly, equal size of races should be considered so that the results would be more representative of Malaysia population. Secondly, future research can also consider to examine whether similar findings would have emerged in young adults from other backgrounds (i.e., lower educational background, social or emotional challenges, low socioeconomic status, etc.). Thirdly, future research may also investigate the behaviours or specific types of activity that contribute to each of the involvement domain. For instance, spiritual involvement may includes talk about meaning of life, attend weekly religious meeting, share values and beliefs, etc. Additionally, as this study has set a base level data on perceived parental involvement which based on young adults from intact families, it is recommended that future work can examine on young adults from other family forms (i.e., dual career family, single parent family, and divorced family).

The present study has several important implications for the parenting research and program. First of all, the findings enhance the existing knowledge regarding Malaysian young adults' long term perception on their parents' involvement. Besides, more informative workshops or talks on how to interact with their children in those significant domains (e.g., companionship, emotional development, sharing activities, etc.) could also be organised to further enhance the involvement that parents have in their children's development.

Lastly, to address the question posted prior in the beginning of this study on whether social changes affect the traditional distribution of parental involvement, this study concludes that the trend of this traditional structure seems to be remained, mothers and fathers do involve differently in their children's development. In particular, mothers were found to be more involved in expressive and MAI. Whilst there is an egalitarian involvement of both parents in instrumental dimension, fathers have found to be more involved in instrumental functions as 
compared to other two dimensions of involvement. As the present study is one of the few studies that research on the different dimensions of parental involvement, more studies are warranted, especially in examining children from different backgrounds.

\section{REFERENCES}

[1] L. Craig, "Does Father Care Mean Fathers Share? A Comparison of How Mothers and Fathers in Intact Families Spend Time with Children," Gender and Society, Vol. 20, 2006, pp. 259-281. doi:10.1177/0891243205285212

[2] T. Parsons, \& R. F. Bales, "Family, Socialization, and Interaction Process,” Glencoe, IL: Free Press, 1995.

[3] K. Singh, P. G. Bickley, P. Trivette, T. Z. Keith, P. B. Keith and E. Anderson, "The Effects of Four Components of Parental Involvement on Eighth-grade Student Achievement: Structural Analysis of NELS-88 Data," School Psychology Review, Vol. 24, No. 2, 1995, pp. 299-317.

[4] M. E. Lamb, J. H. Pleck, E. L. Charnov, \& J. A. Levine, "A Biosocial perspective on Paternal Behavior and Involvement. In J. Lancaster, J. Altmann, A. Rossi, \& L. Sherrod (Eds.)," Parenting across the lifespan: Biosocial dimensions, New York: Aldine de Gruyter, 1987, pp. 111-142.

[5] Y. Mo and K. Singh, "Parents' Relationship and Involvement: Effects on Students' School Engagement and Performance," Research in Middle Level Education Online, Vol. 31, No. 10, 2008, pp. 1-11.

[6] T. Parsons, “The Social System,” Glencoe, IL: The Free Press, 1951.

[7] G. E. Finley and S. J. Schwartz, "The Father In-volvement and Nurturant Fathering Scales: Retrospective Measures for Adolescent and Adult Children," Educational and Psychological Measurement, Vol. 64, 2004, pp. 143-164. doi:10.1177/0013164403258453

[8] G. E. Finley, S. D. Mira and S. J. Schwartz, "Perceived Paternal and Maternal Involvement: Factor Structures," Mean Differences, and Parental Roles. Fathering, Vol. 6, No. 1, 2008, pp. 62-82.doi:10.3149/fth.0601.62

[9] L. Thompson and A. J. Walker, "Gender in Families: Women and Men in Marriage, Work, and Parenthood. In A. Booth (Ed.)," Contemporary families: Looking forward, looking back, Minneapolis, MN: National Council on Family Relations, 1991, pp. 76-102.

[10] J. Kellerman and E. R. Katz, "Attitudes towards the Division of Child-rearing Responsibility,” Sex Roles, Vol. 4, 1978, pp. 505-513.doi:10.1007/BF00287195

[11] N. Noor, "Roles and Women's Well-being: Some Preliminary Findings from Malaysia,” Sex Roles, Vol. 41, 1999, pp. 123-145. doi:10.1023/A:1018846010541
[12] W. Yeung, J. Sandberg, P. Davis-Kean and S. Hofferth, "Children's time with Fathers in Intact Families," Journal of Marriage and Family, Vol. 63, 2001, pp. 136-154. doi:10.1111/j.1741-3737.2001.00136.x

[13] J. Z. Giele and E. Holst, "New Life Patterns and Changing Gender Roles," Advances in Life Course Research, Vol. 8, 2004, pp.3-22. doi:10.1016/S1040-2608(03)08001-8

[14] M. E. Lamb, J. H. Pleck, E. L. Charnov and J. A. Levine, "Paternal Behavior in Humans," American Zoologist, Vol. 25, 1985, pp. 883-894.

[15] W. Marsiglio, P. Amato, R. D. Day and M. E. Lamb, "Scholarship on Fatherhood in the 1990s and beyond," Journal of Marriage and Family, Vol. 62, 2000, pp. 1173-1191.doi:10.1111/j.1741-3737.2000.01173.X

[16] A. B. Andrews, I. Luckey, E. Bolden, J. Whiting-Fickling and K. A. Lind, "Public Perceptions about Father Involvement: Results of a State Wide Household Survey," Journal of Family Issues, Vol. 25, 2004, pp. 603-633. doi:10.1177/0192513X03258303

[17] G. E. Finley and S. J. Schwartz, "Parsons and Bales revisited: Young Adult Children's Characterization of the Fathering Role,” Psychology of Men and Masculinity, Vol. 7, 2006, pp. 42-55.doi:10.1037/1524-9220.7.1.42

[18] S. Hofferth, "Race/ethnicity Differences in Father Involvement in Two-parent Families: Culture, Context, or Economy?” Journal of Family Studies, Vol. 24, 2003, pp. 185-196.

[19] D. W. Shwalb, H. Kawai, S. Shoji and K. Tsunetsugu, "The Middle Class Japanese Father: A Survey of Parents of Preschoolers," Journal of Applied Developmental Psychology, Vol. 18, 1997, pp. 497-511. doi:10.1016/S0193-3973(97)90024-1

[20] J. F. Toth, Jr. and X. Xu, "Ethnic and Cultural Diversity in Fathers' Involvement: A Racial/ethnic Comparison of African American, Hispanic, and White fathers," Youth and Society, Vol. 31, 1999, pp. 76-99. doi:10.1177/0044118X99031001004

[21] Z. Hossain and M. C. Anziano, "Mothers' and fathers' Involvement with School-age Children's Care and Academic Activities in Navajo Indian Families," Cultural Diversity and Ethnic Minority Psychology, Vol. 1, No. 2, 2008, pp. 109-117.

[22] U. W. Ebner-Priemer, J. Kuo, S. S. Welch, T. Thielgen, S. Witte, M. Bohus and M. M. Linehan, "A Valence-dependent Group-specific Recall bias of Retrospective Self-reports: A Study of Borderline Personality Disorder in Everyday Life," The Journal of Nervous and Mental Disease, Vol. 194, 2006, pp. 774-779.

doi:10.1097/01.nmd.0000239900.46595.72 